\title{
HIGH SCHOOL PEER BUDDY PROGRAM: IMPACT ON SOCIAL AND ACADEMIC ACHIEVEMENT FOR STUDENTS WITH DISABILITIES
}

\author{
Ragea Alqahtani, PhD \\ Najran University, Saudi Arabia \\ Francie R. Murry, PhD \\ University of Northern Colorado, USA
}

\begin{abstract}
The purpose of this study was to examine the Peer Buddy Program at a high school for students with disabilities (i.e., learning and behavior disabilities) in academic and social achievement. Two specific questions were addressed: Do students with learning and/or emotional/behavioral disabilities, who are participating in the Peer Buddy Program, show improvement in their use of social skills according to self-report, special and general curriculum teacher ratings on a standardized social skill rating scale? and 2) Do students with learning and/or emotional/behavioral disabilities, who are participating in the Peer Buddy Program, show improvement in academic skill use according to past to present year comparisons on grade point averages, and special education informal assessments (Fast Math, System 44, and Acuity)? Student, special and general education teachers' ratings on the Social Skills Achievement Scale (SSIS) and student archival records data was examined through pair $t$-test analyses pre and post the Peer Buddy Program intervention. The results indicated that the Peer-Buddy Program had a positive impact on the social and academic achievement of high school students with learning and behavioral disabilities.
\end{abstract}

Keywords: Peer buddies, emotional and behavioral disabilities, learning disabilities, peer mediation, peer support

\section{Introduction}

Students with learning disabilities (LD) and with emotional and behavioral disabilities (EBD) have poor outcomes after graduating from high school (Carter, Cushing, Clark, \& Kennedy, 2005). They face worse outcomes if they are part of the one-fourth of all students with disabilities 
ages, 14-21, who drop out of school (Snyder \& Dillow, 2011). The National Longitudinal Transition Study-2 (Wagner, Newman, Cameto, Garza, \& Levine, 2005) showed that in comparison to their same age peers within the 6 years after leaving high school, students with disabilities were less likely to enroll in post-secondary education; less likely to complete schooling if they do enroll, less likely to be employed, and more likely to have been stopped by the police and twice as likely to have been arrested.

Five barriers have been identified that impede the after high school success of students with disabilities. These barriers include high drop-out statistics, low graduation rates, high unemployment, and lack of social and academic skills (Blackorby \& Wagner, 1996; Newman, Wagner, Cameto, \& Knokey, 2009). In general, adolescents with disabilities have more complex difficulties that interfere with their completion of high school as successfully as their peers without disabilities (Carter et al., 2005; Wagner, et al., 2005). Adolescents with disabilities faced these same problems prior to entering high school, during high school, and after leaving high school.

Blackorby and Wagner (1996) found that approximately twice as many students with disabilities drop out of high school for every one of their peers without disabilities. The National Longitudinal Transition Study-2 (Wagner, et al., 2005) found 38\% of students with disabilities drop out of school compared with their peers who drop out at a rate of $25 \%$. Another study indicated that $85 \%$ of students with disabilities drop out of school (Morris, Ehren \& Lenz, 1991). Adolescents with disabilities who dropout of school typically experience social skill deficits, lack a social network, do not participate in their communities' activities, do not maintain full-time jobs, nor do they live independently, or maintain relationships (Groce, 2004).

\section{Importance of the Study}

Adolescents with disabilities who have difficulties which impact their acquisition of social and academic skills and in turn, influence their displays of achievement negatively, will struggle at the secondary education level and in employment unless intensive interventions are implemented (Candace \& Sharon, 1998; Carter, Sisco, Chung, \& Stanton-Chapman, 2010; Cheney \& Bullis, 2004; Elksnin \& Elksnin, 2006; Malmgren, Edgar, \& Neel, 1998). The focus on academic and social skills growth for students with disabilities has long been viewed as important (US. Department of Education, 2009). They became even more necessary with the implementation of No Child Left Behind (NCLB, 2002) and the reauthorization of Individual with Disabilities Education Act (2004) as more students with disabilities began receiving educational services in inclusive settings than ever before (U.S. Department of Education, 2009). The movement into more inclusive settings created a 
need for students with disabilities to be able to use effective social skills as well increase competence in the use academic skills.

The objectives of this research were to examine increased social and academic achievement by high school students with disabilities participating in a Peer Buddy Program. The examination is of considerable importance given that by the time most students with learning disabilities or emotional/behavioral disabilities have reached high school they are considered to have reached their maximum learning. They are given support toward job placement or completion of high school; however, they are not expected to make large gains or significant changes in grade point average or increases on standardized test results, let alone significant social advancements. This study not only examined the academic growth of the students with disabiltiies but also examined how adults in the environment viewed the behavioral and social growth attributed to student involvement in the Peer Buddy Program. Two questions were specificially addressed regarding the impact of the high school Peer Buddy Program. They were 1) Do students with learning and/or emotional/behavioral disabilities, who are participating in the Peer Buddy Program, show improvement in their use of social skills according to self-report, special and general curriculum teacher ratings on a standardized social skill rating scale? and 2) Do students with learning and/or emotional/behavioral disabilities, who are participating in the Peer Buddy Program, show improvement in academic skill use according to past to present year comparisons on grade point averages, and special education informal assessments (Fast Math, System 44, and Acuity)?

The bulk of studies found in the literature review on peer supports that have been found effective for the enhancement of social and academic skills for students with disabilities andthat these skills have been taught as isolated components from one another rather than as a cohesive program. The research provided has shown that peer support programs and intensive academic programs with peer supports, targeting the increase of individual skills, have had successful outcomes for adolescents with intellectual disabilities and students with Autism Spectrum Disorder, however, not for high school students with emotional/behavioral disabilities.

Learning disabilities and emotional/behavioral disabilities adversely affect educational performance amongst a great many students and interfere in skill acquisition for career performance or employability and most notably interfere with and thus, are identified through social skill use deficits. Given the political and social movements for inclusive education being the first and foremost placement for students with a disability, it is extremely important that a thorough examination of promising interventions be performed (Jackson, Ryndak, \& Wehmeyer, 2008, 2009). Peer support interventions are considered an important element in promoting inclusion. By developing 
students' skills and effectively implementing peer support interventions in the general classroom environment, such supports are more than likely to be adopted, maintained, and to become common place (Schwartz \& Baer, 1991).

A great deal of recent research has examined the changing roles that peers play for students with severe disabilities (e.g., Autism, Intellectual Disabilities, Physical/Orthopedic Disabilities) during adolescence and the environmental factors influencing the development of social relationships between students with and without disabilities (e.g., Brown \& Klute, 2003; Gifford-Smith \& Brownell, 2003, Carter, Sisco, Brown, Brickham, and AlKhabbaz, 2008). Many of the examined social interactions between students with disabilities and their classmates without disabilities took place in the preschool and elementary settings (e.g., Dymond \& Russell, 2004; Katz, Mirenda, \& Auerback, 2002), but little is known about the interactions between students with disabilities and their peers without disabilities in secondary inclusive general education classrooms.

\section{Peer Support Programs}

Research in the area of peer support as an intervention for social skills development has indicated encouraging results between students with disabilities and their peers without disabilities. The bulk of research on peer support interventions has been completed with students who have mild to severe physical and/or intellectual disabilities.

Copeland et al. (2004) found that students who acted as peers in the peer support program believed that the students with disabilities in the program had more positive outcomes than those who were not in the program. Students reported that they thought the peers they worked with were provided appropriate opportunities for social interaction and even showed increased functional academic skills. The peers who acted as supports after the program was completed had higher expectations for their peers with disabilities, assisted students with disabilities to accomplish more, had more positive attitudes toward peers with disabilities, developed friendships with peers with disabilities, introduced their peers and their teachers to peers with disabilities, and described increased levels of fun when with the students with disabilities.

Carter et al. (2005) collected data that showed peer support interventions were effective in developing the social skills of the students with disabilities when they were working with more than one peer. According to the U.S. Department of Education (1996) of the total number of adolescents with disabilities, $29 \%$ need social skills instruction after leaving high school. Supporting adolescents with disabilities socially is an extremely important procedure for ensuring that adolescents with disabilities interact 
normally with their peers, families, and within their communities. The fundamental procedure for the development of social skills for adolescents with disabilities is creating effective models to improve their social interactions (Goldstein, Glick \& Gibbs, 1998). Bandura (2000) suggested a modeling strategy that supports the ideology that learning happens through observing others and imitating their actions.

The effectiveness of the peer support on the interactions and academic engagement of 23 secondary grade level students with disabilities within inclusive classrooms found that there was little to no social and task related discussions or conversations during one-fourth of the observations of the students with disabilities and their peers without disabilities (Carter et al., 2008). When conversations did take place there was a balanced exchange of reciprocal social and task related topics.

In the United States students with disabilities must receive access with the support of resources and supplemental materials for the general education content to the same extent as their nondisabiled peers (IDEA 2004). Therefore, educational programs must be effective in developing student social skill use, input and output of language, reading, writing, mathematics, and other academic skills that they will need to live successful and independent lives after leaving high school (Lehr, Hansen, Sinclair, \& Christenson, 2003). Peer-Assisted Learning Strategies (PALS) supports the use of many materials for assisting students to understand concepts being taught and it uses rewards and reinforcement procedures that promote academic sharing among students with disabilities and their peers (Barley et al., 2002).

Stowitschek, Hecimovic, Stowitschek, and Shores (1982) found significant results when they implemented a peer-mediated intervention with students with emotional and behavioral disorders. They found statistically significant positive gains in spelling with a mean effect size of 2.42 and a range of 0.69 to 3.00. This study included 12 students in a peer tutoring program where peers without disabilities provided academic support in the development of spelling skills to students with emotional and behavioral disorders for 40 fifteen-minute sessions. The peers without disabilities were same ages as the students with EBD, which ranged from 14 to 17 years.

\section{Method}

A paired samples $t$-test research design was used to collect two sets of data from the same sample group as outlined by Gravetter and Wallnau(2009). Grade point average (GPA), social skill ratings (SSIS), and informal special education assessment scores were collected from the students school files as pre-measures. Participation in the Peer Buddy Program was considered the intervention and then the same measures from 
students' archival school files listed above were collected again 1 year later as post-measures.

The high school (grades 9-12) where this study was completed was located in a rural region of Colorado (USA), with a population of approximately 600 students, of which 29 students in the special education program were potential study participants. The ethnicity breakdown for the high school was $2(.3 \%)$ African American; 3 (.5\%) American Indian; 9 (1.4\%) Asian; 46 (7.4\%) Hispanic; 0 (0\%) Pacific Islander; 0 (0\%) 2 or more races; and 564 (90\%) Caucasian. The school had 35 full-time teachers, who provided an approximate student/teacher ratio of 17:6. The socio-economic status was identified as moderate to high based upon $13 \%$ of the student population found eligible for discounted/free lunch.

\section{Peer Buddy Program Description}

The creation of the Peer Buddy Program in this study was adapted from the model described by Hughes et al. (1999). The adaptiaon provided for a to focus not only on socialization but academic growth as well. The program studied was designed to provide supports for both the social and academic skills of students with learning disabilities and behavioral/emotional disabilities in order to allow them access to the general education content areas and emphasize inclusion in social school activities. The program provided these supports through matching peers without disabilities with their peers with disabilities in the general content area courses where they were scheduled together or during a scheduled class in the special education program where they could work together on content area assignments.

\section{Social Skills Improvement System (SSIS)}

The SSIS analyzes and measures social behavior according to the self-perceptions of children/youth, parents and teachers (Gresham, 2010). The scale has been validated for use on children/youth ages five to eighteen. It measures interpersonal strengths, family involvement and school functioning. For example, items on the Student Form that measure interpersonal strengths include, "I try to forgive others when they say sorry". On the Teacher Form an item example for School functioning is, "Pays attention to your instruction". On the Parent Form, an item example for family involvement is, "Follows household rules".

The SSIS is used widely in schools as well as social agencies. McFall (2008) conducted many studies to determine convergent validity of SSIS. According to a study conducted by Epstein (2008), a correlation of eightyeight percent existed between SSIS and Child Behavior Checklist, another widely used instrument for behavioral problem identification. In another 
study that aimed at determining convergent reliability, a portion of Gresham Behavior Rating Scale portrayed a strong relationship with the Child Behavior Checklist (Merrell, 2010). The child Behavior checklist is a consistent and strong indicator of skills for interpersonal strength use at school. The correlation is quite high for the social functioning relationship with the externalizing scale on Child Behavior Checklist (Emerson, 2010).

According to Quinn (2009), the SSIS adequately fulfills the requirements of discriminant validity. It has been found to effectively discriminate children and adolescents with behavior and learning disabilities from those without. For instance, the assessment of intrapersonal and interpersonal strengths helps in evaluation of learning disabilities (Merrell, 2009). Besides, assessment of family involvement and school functioning is imperative in assessment of behavioral disorders. The preciseness of the two assessments makes SSIS valuable in the test of discriminant validity. Furthermore, a close relationship exists between discriminant and content validity (Reamer, 2009).

\section{Fastt Math}

FASTT Math is an informal assessment used to arrive at the fluency and automaticity of the students' basic mathematics fact use. It is also a teaching system once level of ability is ascertained. The technology used steps the student through levels of a mathematics intervention program that assists to develop fluency with basic math facts up to Algebra I (Scholastic, 2011). It helps students to avoid the use of incorrect strategies often used to achieve answers for basic mathematics facts such as finger counting and uses techniques to improve student ability to retrieve answers for basic facts from memory quickly and effortlessly (Scholastic, 2011).

\section{System 44}

System 44 is an informal assessment and a program designed for struggling readers in Grades 3-12. It helps students who lack basic decoding skills understand that the English language is a finite system of 44 sounds and 26 letters that can be mastered (Scholastic, 2011). It uses research-based techniques for phonics, vocabulary, fluency, and comprehension instruction for older students. Emphasis is placed on explicit instruction of the English language, and includes motivations and age-appropriate adaptive technology. The Scholastic Phonics Inventory program (SPI) is embedded in System 44, which tracks progress during the assessment portions. This tracking system supports teachers' ability to know when the students have acquired the knowledge necessary to move to next level. It will also provide corrective instruction when necessary to enhance students' reading skills (Scholastic, 2011). 


\section{Acuity Assessment}

Acuity is a predictive assessment that helps to provide diagnostic measures for grade 3-8 students in language arts. Acuity reports provide standards-aligned performance data, which support an educator's ability to inform instruction at the individual student and class level (McGraw-Hill, 2010).

\section{Data Collection}

The sampling procedure that was used was a volunteer group of high school students with disabilities who were participating in the Peer Buddy Program. The criteria for students to participate in this study was that they were (a) enrolled in the high school, (b) receiving special education services through an individualized education program, (c) participating in the Peer Buddy Program, and (d) provided assent and had parental consent to participate. The conditions stated above were well suited to the purpose of this study and constituted the necessary rationale for using a convenience sampling method (Gall, Gall, \& Walter, 2007).

\section{Archival School Files Review Procedure}

Quantitative information was collected from the students' school files for each participant. The file information included the SISS Rating Scales,from the students, the special and general education teachers, informal special education assessment scores, GPA, general education content area grades, and Individualized Education Plans.

Data were analyzed using a paired samples t-test (Gravetter \& Wallnau, 2009). The primary measure in this study was the Social Skills Improvement System (SSIS) which was administered both pre- and postPeer Buddy Program. The use of the paired samples provided advantages since the sample population was small, treatment conditions that took place over time, and the paired samples could prevent or avoid problems caused by individual differences. The same students completed the SSIS both pre- and post-Peer Buddy Program which eliminated the issues of matching students for age, IQ, and/or gender.

The SSOS scores were analyzed to determine if the mean found on the pre-measure was statistically different from the mean found on the postmeasure scores (Holcomb, 2009). Once pre- and post-measure raw scores for each domain area and totals of the SSIS were entered, a comparison of means test was conducted. Descriptive statistics were generated for the mean, standard deviation, and the standard error mean. 


\section{Results}

To address the initial question posed, a pre- and post- analyses of the SSIS scores for the students was employed using a paired samples $t$-test. The scores from the students, the special education teacher, and general education content teachers regarding the perceived social skills achievement of the students with disabilities were analyzed separately. The SSIS teacher form also included an academic scale, which both the special and general education teachers completed.

The $t$-test from the students' SSIS social ratings equaled -2.62, and the $p$-value equaled .028 , and the $p<.05$. There was a statistically significant difference between means of the pre-SSIS score of students with disabilities' perceptions toward their social skills in the scores $(M=12.53, S D=1.80)$ and their post- SSIS score $(M=14.50, S D=2.81) ; t(9)=-2.63, p=.028$. From the students` perspective the Peer Buddy Program positively improved their use of social skills.

The $t$-test from the special education teachers' SSIS social ratings equaled 5.24 and the $p$-value equaled .001, and the $p<0.05$ indicating that there was a statistically significant difference in the pre-SSIS score of special education teacher's perceptions toward the social skills of students with disabilities $(M=12.17, S D=2.92)$ and the post-SSIS score of the perceptions $(M=15.55, S D=2.87) ; t(9)=-5.24, p=.001, p<.05$. In conclusion, from the perspective of the special education teacher, the Peer Buddy Program increased the high school students with LD and EBD use of social skills.

The $t$-test from the general education teachers' SSIS social ratings equaled -.071 and the $p$-value equaled .95, so $p>0.05$ indicating that there was no statistical significant difference between the pre- SSIS scores of general education teachers' perceptions of the social skills of students with disabilities $(M=11.91, S D=3.97)$ and their post-SSIS scores $(M=12.04$, $S D=4.33) ; \mathrm{t}(9)=-(-.071), p=(0.945)$. The outcome of the SSIS scores from the general education teachers' perceptions was that the Peer Buddy Program had not had a significant impact on the social skills of the high school students with LD and EBD.

To address the question regarding academic acheivement, data from the teacher SSIS form and the student archival records was analzyed. The general and special education teachers completed the SSIS academic competence form before providing the Peer Buddy Program and then again after the Peer Buddy Program. These component measures were also analyzed pre and post Peer Buddy Program using a paired samples $t$-test.

The analyses of the special education teachers" SSIS academic ratings provided a $t(9)=(-7.9)$, and a $p$-value $=(0.000)$ which was $<0.05$, indicating that there was a statistically significant difference between the 
means of pre-SSIS scores $(M=1.4, S D=.62)$ and post SSIS scores $(\mathrm{M}=3.6$, $S D=1.10$ ) of the special education teachers' perceptions toward the academic achievement by the students with LD and EBD. Therefore, the analyses indicated that the special education teacher's perceptive was that the Peer Buddy Program had an influence on the academic achievement of the high school students with LD and EBD.

The analyses of the general education teachers" SSIS academic ratings provided a $t(9)=-1.46, p=(.18)>.05$, indicating that there was no statistically significant difference between the means of pre- SSIS scores and post- SSIS scores mean of the general education teachers' perceptions toward the academic skill development of students with LD and EBD. This result indicated that from the general education teachers' perspective the Peer Buddy Program was not influential on the academic achievement of the high school students with LD and EBD.

\section{Data of Archival Files}

The additional data collected from students' files included the Grade Point Average (GPA) and the special education informal assessments (i.e., FASTT Math, System 44, and Acuity). These data were analyzed before and after the Peer Buddy Program was provided to the high school students with disabilities.

\section{Students' Grade Point Average}

The students' GPA was collected before and after the Peer Buddy Program. The GPA data was analyzed using the $t$-test and the results yielded were as follows: (a) the average of students' pre-GPA was 2.35, (b) the standard deviation of their scores was .82 (c) the standard error score was .82 , (d) the averages of students' post-GPA was 2.58, (e) the standard deviation of their scores was .67, (f) the standard error score was .21, (g) the correlation between the students' pre- and post-GPA was .97, (h) the significant level was .97 , (i) the $t$-test value of the students' pre- and post GPA of -3.12, (j) the lower level of confidence interval was -.39, (k) the upper interval of confidence was -.06, (l) the degree freedom was 9, and (m) p-value was .01.

The results of the analysis was that the students had a higher postGPA than their pre- GPA by.22 points. Furthermore, the difference between the standard deviation of pre-GPA and post-GPA was .23, and the difference between the standard error of pre and post GPA was .07). Since $t$-test equaled -3.12 , and the $p$-value equaled 0.01 , and $p<0.05$, the final result was a statistically significant difference in the scores for students' pre-GPA $(\mathrm{M}=2.35, \mathrm{SD}=.82)$ and students' post-GPA $(M=2.58, S D=.67) ; t(9)=$ $3.11, p=.01$. The results indicate that there was a positive effect of the Peer 
Buddy Program for increasing the academic GPA of the high school students with LD and EBD.

\section{Students' FASTT Math Scores}

The students' FASTT Math scores were collected prior to and after the Peer Buddy Program was provided. The analyzed data resulted in the following: (a) the average of students’ pre FASTT Math scores was 43.90, (b) the standard deviation of their scores was 14.62, (c) the standard error score was 4.62, (d) the average of the students' post FASTT Math was 107.29, (e) the standard deviation of their scores was 56.25, (f) the standard error score was 17.79, (g) the correlation between the students' pre and post FASTT Math scores was .59, (h) the significant level was (j) the lower interval confidence difference was -98.47 , (k) the upper interval confidence difference was -28.31, (l) the degree freedom was 9, and (m) $p$-value was .003 .

The results illustrated the improvement of the students' FASTT Math scores, the difference between pre FASTT Math score and the post FASTT Math score was -63.39 points. Furthermore, the difference between the standard deviation of the pre FASTT Math score and the post FASTT Math score was 49.04, and the difference between the standard error of the pre and the post FASTT Math scores was 15.51. Since $t$-test equaled -4.1, and the $p$-value equaled .003, and the $p<0.05$, the result was that there was a statistically significant difference in the scores for students' pre FASTT Math scores $(M=43.90, S D=14.62)$ and students' post FASTT Math scores $(M=107.29, S D=56.25) ; t(9)=-4.09, p=.003$. The results indicate the positive effect the Peer Buddy Program had on the development of the academic skills of the FASTT Math scores for the high school students with LD and EBD.

The results illustrated the improvement of the students’ FASTT Math scores, the difference between pre FASTT Math score and the post FASTT Math score was -63.39 points. Furthermore, the difference between the standard deviation of the pre FASTT Math score and the post FASTT Math score was 49.04, and the difference between the standard error of the pre and the post FASTT Math scores was 15.51. Since $t$-test equaled -4.1 , and the $p$ value equaled .003, and the $p<0.05$, the result was that there was a statistically significant difference in the scores for students' pre FASTT Math scores $(M=43.90, S D=14.62)$ and students' post FASTT Math scores $(M=107.29, S D=56.25) ; t(9)=-4.09, p=.003$. The results indicate the positive effect the Peer Buddy Program had on the development of the academic skills of the FASTT Math scores for the high school students with LD and EBD. 


\section{Students' System 44 Scores}

The students' pre- and post- Lexcile scores on the System 44 program were analyzed for the Peer Buddy Program students with disabilities. The average of students' pre-Lexcile scores was 627.29, the standard deviation was 278.01, the standard error score was 105.08, the averages of students' post-Lexcile score was 734.86, the standard deviation of the scores was 293.03, the standard error score was 110.75, the correlation between the students' pre- and post-Lexcile scores was .93, the significant level was .002 , the $t$-test value of the students' pre- and postLexcile scores was -2.64 , the lower confidence interval was 207.22, (k) the upper confidence interval was -7.92, (l) the degree freedom was 7; and (m) p-value was .038.

The results determined the difference between the students' preLexcile scores and their post-Lexcile scores was 107.57, the difference between the standard deviation of pre- and post-Lexcile scores was 107.75, and the difference between the standard error of pre- and post-Lexcile scores was 40.72 . Since the $t$-test equaled -2.64 and the $p$-value equaled 0.04 , and $p$ $<0.05$, it can be concluded that there exists a statistically significant difference in the scores for students' pre-Lexcile score $(M=627.29, S D=0$. 278.01) and students' post-Lexcile score $(M=734.86, S D=293.03)$ conditions; $t(9)=-2.64, p=0.038$. The finding suggested that there was a positive impact from the Peer Buddy Program on the changes in System 44 Lexcile reading scores of the high school students with LD and EBD.

\section{Students’ Acuity Scores}

The Acuity test scores were collected before and after implementation of the Peer Buddy Program with students with LD and EBD. The analyzed data showed the following results: (a) the average of students' pre-Acuity scores was 386.75, (b) the standard deviation of their scores was 53.12, (c) the standard error score was 18.78, (d) the averages of students' post-Acuity score was 451.88 , (e) the standard deviation of their scores was 52.83, (f) the standard error score was 18.68; (g) the correlation between the students' pre- and post-Acuity scores was 0.37 , (h) the significant level was 0.37 , (i) the t-test value of the students' pre- and postAcuity scores was -3.09 , (j) the lower interval confidence difference was 114.90, (k) the upper interval confidence difference was -15.35 , (l) the degree freedom was 7, and (m) p-value was .02.

The results determined the difference between the students' preAcuity scores and their post-Acuity scores which was -65.13 , the difference between the standard deviation of pre- and post-Acuity scores which was 59.53, and the difference between the standard error of pre- and post-Acuity scores which was 21.05. Since $t$-test equaled -3.09 and the $p$-value equaled 
.02 , and $p<0.05$ the result revealed a statistically significant difference in the scores for students' pre-Acuity score $(M=386.75, S D=53.12)$ and students' post-Acuity scores $(M=451.88, S D=52.83)$; $(8)=-3.09, p$ $=.017$. The results illustrated the positive impact of the Peer Buddy Program on developing the academic Acuity scores of the high school students with LD and EBD.

\section{Conclusion}

Overall results of the archival file data collection indicated that there was a positive statistically significant difference between the students' GPAs, FASTT Math, System 44, and Acuity scores pre- and post- Peer Buddy Program. The special education teacher's ratings supported the students' statistical significant academic changes indicating that the Peer Buddy Program impacted the academic achievement of the students. These results should encourage special education teachers to consider the implementation of this program in their high school programs for students with LD and EBD. The lack of general education teachers'perception that student academic achievement had changed can be explained by the fact that high school teachers do not typically have consistent contact with students as they may only have them for a single course across a school year, while special education teachers have consistent and engaged contact with their students. With more engaged contact time between the students and the general education teachers a difference in the scores may be seen. Both the students and special education teachers saw growth in the social and behavioral dispositions which is consistent with past research on peer programs that focused on social skill increases. The data results converged and it can be concluded that the Peer Buddy Program had a positive impace on the social and academic achievement of the high school students with LD and EBD.

\section{References:}

Bandura, A. (2000). Self-efficacy and the construction of an optimistic self. Today's Youth, 4(4), 18-22.

Barley, Z., Lauer, P. A., Arens, S. A., Apthorp, H. S., Englert, K. S., Snow, D., \& Akiba, M. (2002). Helping at-risk students meet standards: A synthesis of evidence-based classroom practices. Aurora, CO: Mid-continent Research for Education and Learning.

Bender, W. N., \& Wall, M. E. (1994). Social-emotional development of students with learning disabilities. Learning Disability Quarterly, 17(4), 323336. 
Blackorby, J., \& Wagner, M. (1996). Longitudinal postschool outcomes of youth with disabilities: Findings from the National Longitudinal Transition Study. Exceptional Children, 62(5), 399-414.

Brown, B. B., \& Klute, C. (2003). Friends, cliques, and crowds. In G. R. Adams \& M. D. Berzonsky (Eds.), Blackwell handbook of adolescence (pp. 330-348). Malden, MA: Blackwell.

Candace. S. B., \& Sharon. V. (1998). Strategies for teaching students with learning and behavior problems ( $4^{\text {th }}$ edition). Needham Heights. Viacom Company.

Carter, E. W., Cushing, L. S., Clark. N. M.. \& Kennedy, C. H. (2005). Effects of peer support interventions on students' access to the general curriculum and social interactions. Research and Practice for Persons with Severe Disabilities, 30 (4), 15-25.

Carter, E. W., Sisco, L. G., Brown, L., Brickham, D., \& Al-Khabbaz, Z. A. (2008). Peer interactions and academic engagement of youth with developmental disabilities in inclusive middle and high school classrooms. American Journal on Mental Retardation, 113 (6), 479-494.

Carter, E. W., Sisco, L. G., Chung, Y., \& Stanton-Chapman, T. (2010). Peer interactions of students with intellectual disabilities and/or autism: A map of the intervention literature. Research and Practice for Persons with Severe Disabilities, 35 (3-4), 63-79.

Cheney, D., \& Bullis, M. (2004). The school-to-community transition of adolescents with emotional and behavioral disorders. In R. B. Rutherford, M. M. Quinn, \& S. R. Mathur (Eds.), Handbook of research in emotional and behavioral disorders. New York, NY: Guilford.

Copeland, S. R., Hughes, C., Carter, E. W., Guth, C., Presley, J. A. , Williams, C. R., \& Fowler, S. E. (2004). Increasing access to general education: Perspectives of participants in a high school peer support program. Remedial and Special Education, 26 (6), 342-352.

Dymond, S., \& Russell, D. (2004). Impact of grade and disability on the instructional context of inclusive classrooms. Education and Training in Developmental Disabilities, 39(2), 127-140.

Elksnin, L., \& Elksnin, N. (2006). Teaching social-emotional skills at school and home. Love Publishing: Loveland, CO.

Gall, M. D., Gall, J. P., \& Borg, W. R. (2007) Educational research: An introduction. Boston, MA: Pearson Education.

Gifford-Smith, M. E., \& Brownell, C. A. (2003). Childhood peer relationships: Social acceptance, friendships, and peer networks. Journal of School Psychology, (41), 235-284.

Goldstein, A. P., Glick, B. \& Gibbs, J.C. (1998). Aggression replacement training: A comprehensive intervention for aggressive youth. Research Press: Champaign, IL 
Gravetter, F. J., \& Wallnau, L. B. (2009). Statistics for the behavioral sciences. Belmont, CA: Brooks/Cole, Cengage Learning.

Groce, E. N. (2004). Adoloscents and youth with disability: Issues and challenges. Asia Pacific Disability Rehabilitation Journal, 15(2), 13-32.

Holcomb, Z. C. (2009). SPPS basics: Techniques for a first course in statistics (2nd ed.). Reno, NV: Pryczak Publishing.

Hughes, C., Guth, C., Hall, S., Presley, J., Dye, M., \& Byers, C. (1999). They are my best friends: Peer buddies promote inclusion in high school. Teaching Exceptional Clhildren, 31(5), 32-37.

Indivdiuals with Disabilities Education Improvement Act (IDEA). (2004). 20 U.S. C. $\$ 1401$ et seq.

Jackson, L. B., Ryndak, D. L., \&Wehmeyer, M. L. (2008/2009). The dynamic relationship between context, curriculum, and student learning: A case for inclusive education as a research-based practice. Research and Practice for Persons with Severe Disabilities, 33 (4), 175-195.

Katz, J., Mirenda, P., \& Auerbach, S. (2002). Instructional strategies and educational outcomes for students with developmental disabilities in inclusive "multiple intelligences" and typical inclusive classrooms. Research and Practice for Persons with Severe Disabilities, 27 (4), 227-238.

Lehr, C. A., Hansen, A., Sinclair, M. F., \& Christenson, S. L. (2003). Moving beyond dropout prevention to school completion: An integrative review of data-based interventions, School Psychology Review, 32(3), 342364.

Malmgren, K., Edgar, E., \& Neel, R.S. (1998). Postschool status of youths with behavioral disorders. Behavioral Disorders, 23 (4), 257-263.

Morris, J.D., Ehren, B.J., \& Lenz, B.K. (1991). Building a model to predict which fourth through eighth graders will drop out in high school. The Journal of Experimental Education, 59(3), 286-293.

Newman, L., Wagner, M. Cameto, R., \& Knokey, A. M. (2009). The posthigh school outcomes of youth with disabilities up to 4 years after high school. A report from the National Longitudinal transition Study-2 (NLTS-2). Prepared for the U.S. Department of Education (NCSER2009-3017). Retrieved from http://www. nlts2.org/reports/2009_04/nlts2_report_2009_04_complete.pdf No Child Left Behind (NCLB) Act of 2001, Pub. L. No. 107-110 §115, Stat. 1425 (2002).

Schwartz, I. S., \& Baer, D. M. (1991). Social validity assessments: Is current practice state of the art? Journal of Applied Behavior Analysis, 24(2), 189204.

Snyder, T. D., \& Dillow, S. A. (2011). Digest of education statistics 2010 (NCES 2011-015). Washington, DC: National Center for Education Statistics, Institute of Education Sciences, U.S. Department of Education. 
Stowitschek, C., Hecimovic, A., Stowitschek, J., \& Shores, R. (1982). Behaviorally disordered adolescents as peer tutors: Immediate and generative effects on instructional performance and spelling achievement. Behavioral Disorders, 7(3), 136-148.

U.S. Department of Education (1996). 18th annual report to Congress on the implementation of the Individuals with Disabilities Education Act, 2006. Washington, DC: Author.

U.S. Department of Education (2001). Twenty-second annual report to Congress on the implementation of the Individuals with Disabilities Education Act, 2006. Washington, DC: Author.

U.S. Department of Education (2009). 28th annual report to Congress on the implementation of the Individuals with Disabilities Education Act, 2006. Washington, DC: Author.

Wagner, M., Newman, L., Cameto, R. Garza, N. \& Levine, P. (2005). After high school: A first look at the postschool experiences of youth with disabilities. A report from the National Longitudinal Transition Study-2 (NLTS2). Menlo Park, CA: SRI International. 